\title{
THE CONSTRUCTION OF NORMAL STANDARDS FOR CARDIAC OUTPUT IN MAN
}

\author{
By J. M. TANNER ${ }^{1}$ \\ (From the Laboratory of Therapeutic Research, University of Pennsylvania Medical School; \\ the Anthropological Laboratory, Department of Human Anatomy, Oxford University; and \\ the Sherrington School of Physiology, St. Thomas's Hospital, London University)
}

(Submitted for publication January 14, 1949)

\section{INTRODUCTORY AND THEORETICAL}

The present method of calculating normal cardiac output standards in man involves a fallacy, and has led in practice to erroneous conclusions (1). This is a serious matter for clinicians, since it has been shown by Starr that the first indications of symptomless heart disease may be given by abnormalities in cardiac output (2). Thus it is reasonable to suppose that in the next few decades the determination of cardiac output will become as common as that of basal metabolism, or more so. Consequently it is the object of this paper to present new standards, based on more adequate statistical methods. Use has been made of the data already in the literature, of a new series of 50 subjects so far only reported in abstract (3), and of partly published data on 174 normal individuals collected by Starr and his co-workers.

The introductory and theoretical part of this paper refers to the construction of cardiac output standards irrespective of the method used for measuring output. The main standards developed thereafter refer to the Starr ballistocardiograph; in this connection a new constant for use in the Starr formula for stroke volume is given. Lastly, some biometric relations between the various methods are examined, and as a result tentative recommendations with regard to cardiac catheterization data are made. There are at present insufficient catheterization data available on normal subjects from which to decide whether the same standards may be used as for the ballistocardiograph. In any case the ballistocardiograph seems the more appropriate instrument to use in determining whether a person is slightly abnormal or not.

\footnotetext{
1 Present address: Sherrington School of Physiology, St. Thomas's Hospital, London S.E. 1, England.
}

\section{Material}

The material used in this analysis comes from three sources. Firstly, Table I reports measurements made personally with the ballistocardiograph on 50 healthy young men, when I was working in Dr. Starr's laboratory in 1943. In this study classification of physique by Sheldon's method (4) was undertaken and the somatotypes of the subjects are given in the last column; I am indebted to Dr. W. C. Dupertuis for help in this aspect of the work. Secondly, the raw data of the extensive ballistocardiographic series of 200 healthy persons reported by Starr and Schroeder in 1940 (5) have been available to me. This series is of particular value because the subjects have been followed for eight to ten years (2) and those now suffering from any cardiovascular disease have been eliminated from the present calculations, leaving 174 persons. Thirdly, in the last section of the paper, use has been made of all the substantial and detailed series of cardiac output data in the literature, including results obtained by catheterization, acetylene and ethyl iodide methods.

The reliability of cardiac output determinations and the relations between results obtained by different methods

Two points must be considered before undertaking a detailed and thus laborious biometric analysis of cardiac output data. First of all, it is clearly useless to construct standards for a physiological function which changes greatly from minute to minute or day to day in an unpredictable manner. We must first enquire what is the reliability ${ }^{2}$ - the repeatability-of the measurement.

2 Reliability must of course be clearly distinguished from validity. Reliability refers to how repeatable the measurement in question is, and validity to whether it in fact measures what it purports to measure. Clearly any 
TABLE I

Ballistocardiograph cardiac output data for 50 healthy young men

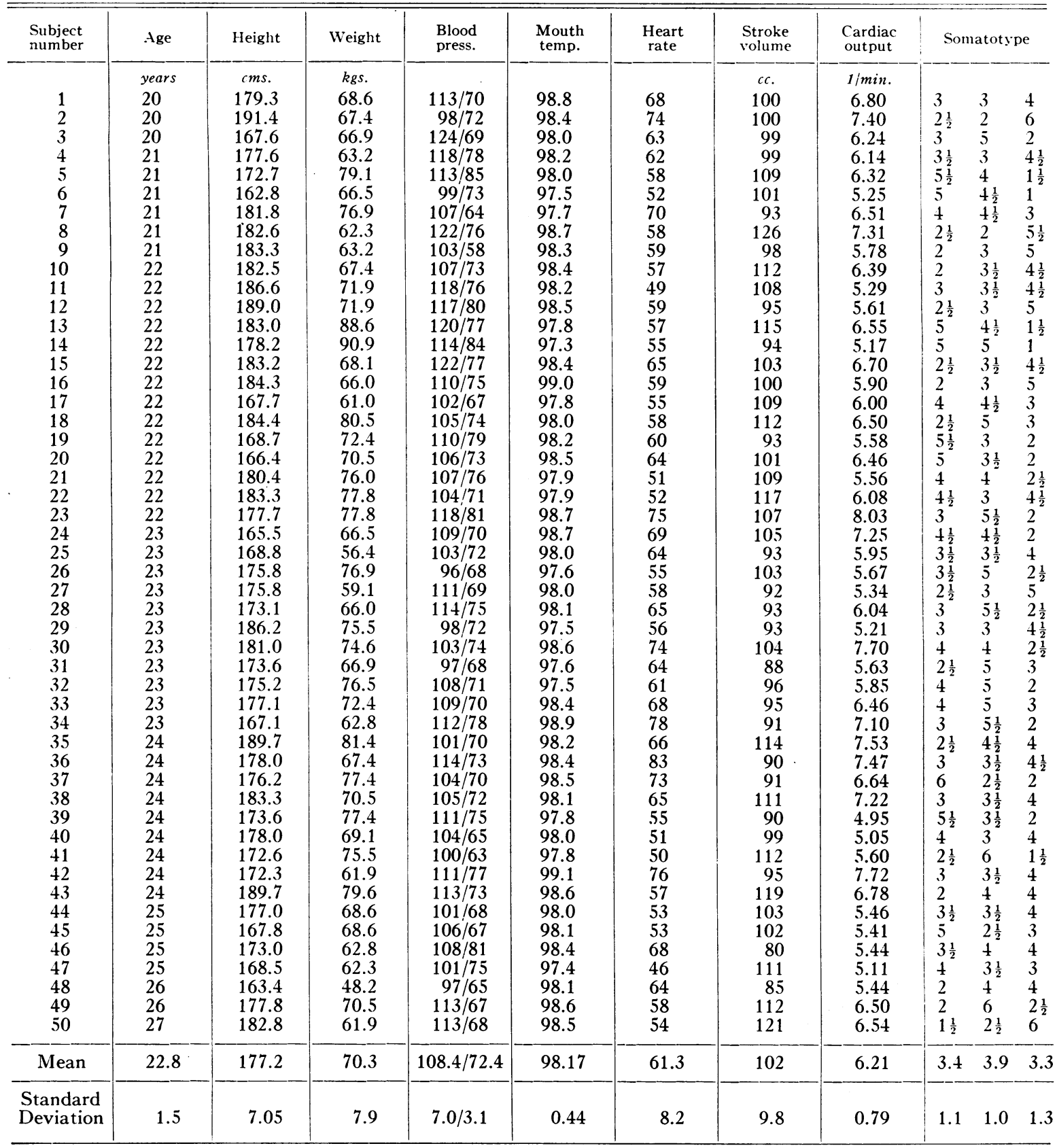

This point must be emphasized simply because, at least in its statistical aspects, it has been thoroughly neglected by physiologists and clinicians, who often instead assume their measurements to

measurement which is not reasonably reliable cannot be valid, but the converse does not hold. be a great deal more reliable than they really are. The simplest way of quantitating reliability is by giving the correlation coefficient between two determinations, the second taken a few minutes or days after the first. This test-retest correlation is known as the coefficient of reliabilit'. Despite 
its importance, it has only been reported for one cardiac output method, the Starr ballistocardiograph; various more or less vague statements are all that we have to go on for other techniques. In estimations by the ballistocardiograph the reliability obtained from two tests seven minutes apart on subjects well rested, so that variation of the cardiac output with the passing of time is minimised, is 0.91 (3). The data given by Starr et al. (6) lead to a very similar figure for the ethyl iodicle method. The statement by Grollman (7) that a retest nearly always falls within $10 \%$ of the initial value indicates that a similar figure would be a reasonable approximation for the acetylene method; while the catheterization method would seem to be slightly less reliable, from the statements of Nickerson et al. (8) and Warren et al. (9).

Though this reliability is certainly high enough to make the construction of standards worth while, it is not nearly so high as for physical measurements, or indeed as for the impressionistic assessment of physique by a skilled observer. This brings us to the second point. Can a single standard be constructed which applies to all methods of measuring cardiac output, in particular to the ballistocardiogram and to the catheterization methods? He would be a bold man who asserted unequivocally that such a standard is possible and can be constructed with present data. But he would be rash, also, who maintained one method's standards have no bearing on another's; for the quantitative relations between two methods are a subject for biometrical analysis, and arguments from the superior validity of one particular method, however justified, are not relevant to this particular problem.

The published results show an astonishing agreement between the different methods under most circumstances, when due regard is paid to the relatively low reliability of each method. The point is this: method A cannot correlate any better with method $B$ than it does with itself, and probably correlates with $\mathrm{B}$ a good deal less. When comparing methods $\mathrm{A}$ and $\mathrm{B}$, however, it is possible by statistical means to neutralize the unreliability of the tests, and see how closely the two methods would agree if they were not subject to such troubles; to find the true correlation of the phenomena measured, were the methods of meas- urement not fallible. This is known statistically as correcting the coefficient for attenuation, and is done simply by dividing the method A-method B correlation by the square roots of each method's reliability coefficient (10). The Starr ballistocardiograph stroke volume for 25 subjects, covering wide age and surface area ranges, correlated with the ethyl iodide stroke volume to the extent of 0.86 (6). When corrected for attenuation so as to represent the true correlation between methods when the unreliability is taken away, this figure becomes $\frac{0.86}{\sqrt{0.91 \times 0.90}}=0.96$. This indicates that $0.96^{2}=0.92$ or $92 \%$ of the variance of each method is due to the factor common to the two methods, and only $8 \%$ to factors specific to each method. More important is the correlation of the Starr ballistocardiograph stroke volume with the catheterization stroke volume (11). For 14 subjects, covering a wide age range, and including normal people and sick patients, the figure was 0.94 . The figure is slightly inflated by the average of two ballistic records being taken, and by the inclusion of aortic cross-section in the old Starr formula. This figure, corrected for attenuation, reaches unity, and if not inflated from these causes, could scarcely be under 0.95 . Lastly, the Nickerson low-frequency critically-damped ballistocardiograph gave a correlation coefficient of 0.83 with the catheterization figure for 54 observations over a wide age span of patients without heart disease. This corrected would again be of the order of 0.95 , and at least with this instrument "variations in arterial pressure, heart rate and age appear to cause no significant variation in the relationship between the cardiac index as measured by the ballistic method and as determined by the catheter method" ( 8 ). Thus these methods agree well, at least for healthy persons at rest; and it is from these that we obtain normal standards and measure our degree of abnormality.

\section{The fallacy of the present ratio standard}

Two expressions have so far been proposed for cardiac output standards; the output per surface area (12) and the output per body weight (5). The implications of the use of these ratios as standards do not seem to have been generally realised; the subject has been discussed at length 


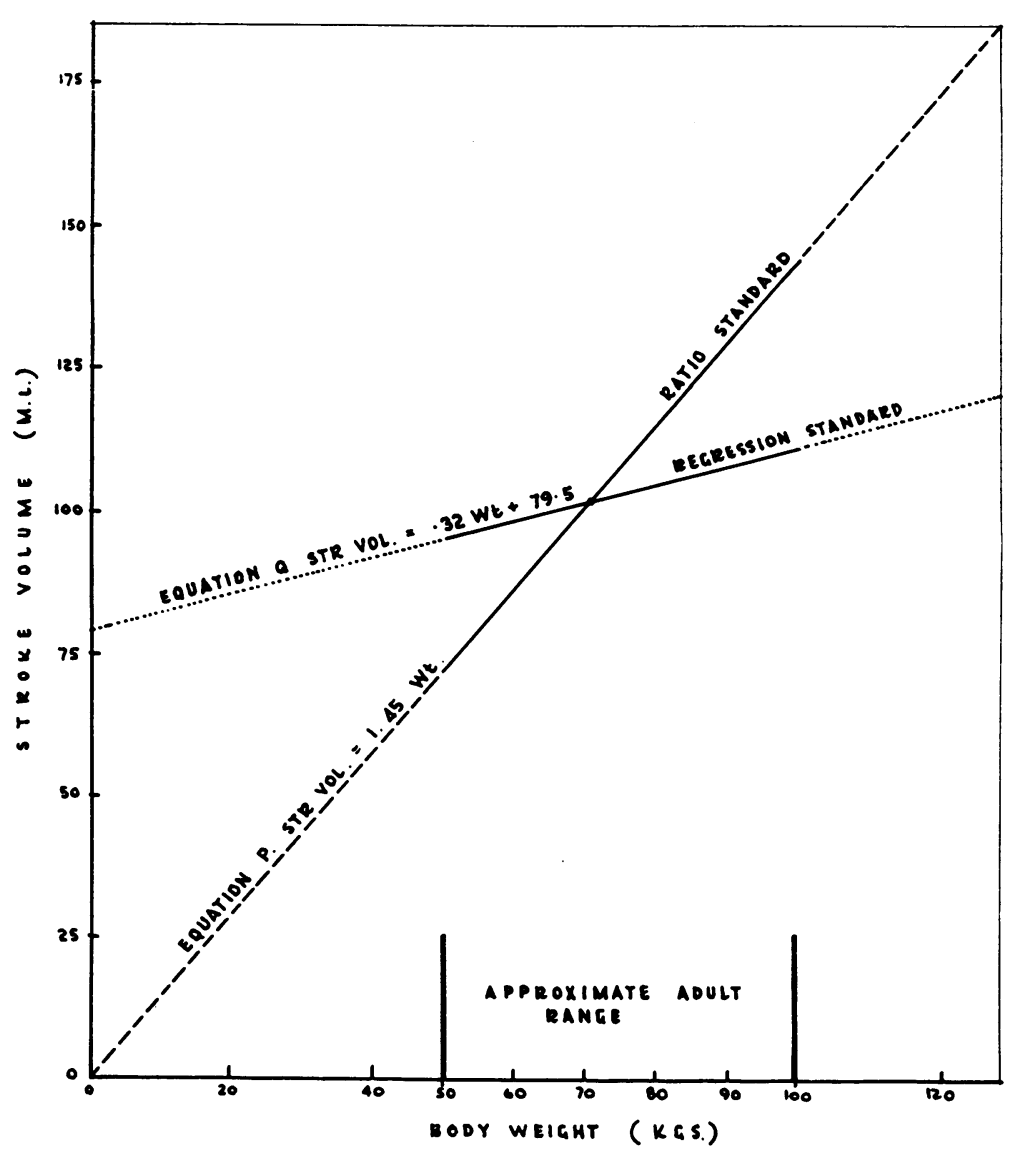

Fig. 1. The Relation of Stroke Volume and Body Weight

elsewhere (1). Except in a special case, not met by cardiac output figures, the ratio standard creates of itself a tendency to say large men have small stroke volumes and small men large ones and thus leads to the situation where large and small men are reported as abnormal more readily than are the medium sized.

This comes about in the following way. Figure 1 shows the stroke volume of the heart plotted against body weight (data of Table I). The use of the ratio, per-weight, standard implies that in the normal person, the stroke volume is proportional to the weight: in fact that the expression,

$$
\text { Stroke Volume }=\mathrm{k} \text {. Wt., }
$$

holds good over the range of values of weight for which the standard is used; that is, for all normal adult values. The constant $\mathrm{k}$ is determined by the mean values of the series of data on which the standard is founded. Thus the line in equation $\mathrm{P}$ passes through the point of the two means, and, by virtue of the form of the equation, through the origin also. If this line were really a newly constructed per-weight standard, we should judge any given stroke volume as normal or abnormal according to how far away from the line our value fell. This is the current practice, using either the per-weight or per-surface area standard. Now actually this expression by no means represents the mathematically "best" or "true" relation between stroke volume and weight over the range of adult values. The best relation is that given by the regression equation (assuming rectilinearity of regression, which is justified at least as a first approximation), and this equation is:

Stroke Volume $(\mathrm{ml})=..32 \mathrm{wt} .(\mathrm{kg})+.79.5 .(\mathrm{Q})$

This is the line called equation $Q$ in Figure 1, and it will be seen that it only coincides with that of 
equation $\mathrm{P}$ at one point, the means. Equation $\mathrm{P}$ should be our proper standard, and it can be seen from the figure that a heavy man of $90 \mathrm{~kg}$. will be given by the ratio standard a "normal" stroke volume which is too high, by as much, in this instance, as $20 \%$. At the end of this paper the example chosen to illustrate the application of the new standards also illustrates this point.

The regression equation also has the advantage that a precise test of significance of the difference between the values found and those predicted is available. That is, confidence limits can be precisely specified, such that only one normal man in 20 , or one in 100 , as is wished, is reported wrongly as abnormal. A similar test is not so readily available for the ratio standard.

\section{The multiple regression equation standard in theory}

Correct normal standards of cardiac output should be constructed, then, from the regression equations found experimentally in healthy people. We not only wish to have standards for every weight, but also for each age, for either sex, and indeed for the varying conditions of all the variables upon which, in the normal individual, stroke volume depends. The more precise the standard for the normal, the smaller the variation we shall be able to identify as abnormal, and the earlier the diagnosis of disorder. What we need is a multiple regression equation in which is shown the dependence of stroke volume upon many variables, each with its own effect separated off from the effects of the others. Stroke volume, we may say, is given (in the normal) by

$$
\mathrm{V}_{\mathrm{s}}=\mathrm{aL}+\mathrm{bM}+\mathrm{cN}+\mathrm{dO}+\mathrm{eP},
$$

where $L, M, N$, etc. are such variables as weight, age and sex, and a, b, c, etc. are coefficients. Such an equation assumes that the relationships between all the variables concerned are linear, though there is no reason why more complicated functions either stated curvilinearly or reduced to linearity by taking logarithms or by some other means should not be used if they represent the data better. Our present data warrant no other assumption than that of linearity, except possibly in the case of age. Multiple regression equations of this sort are used in the newer tables of children's weights, and have been constructed by pathologists to help them identify abnormal tissues (13). A very full and exemplary treatment of their construction and use for basal metabolism standards will be found in Harris and Benedict's monograph (14).

Cardiac output per minute is a physiologically important but composite variable, and its components, stroke volume $\left(\mathrm{V}_{\mathrm{s}}\right)$ and heart rate, are governed by factors which are to a large degree independent of each other (as signified by $V_{s}$ and heart rate having a negative correlation at rest of about -.4). Both stroke volume and heart rate are of very considerable interest in themselves, and it would therefore seem best to have standards for these two variables, as well as for cardiac output per minute. It could then immediately be seen whether a person with a high cardiac output had it because of a high heart rate for, let us say, his age and sex, or a high stroke volume for his size, age and heart rate.

The variables that enter into the multiple regression equations depend, of course, on the correlations found empirically for healthy people. But $a$ priori we may surmise that we should allow for age, sex, and body size and shape. Height, weight and surface area are merely crude ways of considering physique; these relations will be discussed in more detail in the next section. Our theoretical equations may then be:

Stroke Volume $=$ a. Body Size factor + b. Age + c. Heart rate $+d$. Chest dysplasia + e. Androgeny of Phy-

sique $+\mathrm{f} \ldots \ldots \ldots \ldots \ldots \ldots \ldots \ldots \ldots \ldots \ldots \ldots \ldots \ldots \ldots \ldots \ldots$ (B)

Heart Rate $=a^{\prime}$. Body Size factor $+b^{\prime}$. Age $+c^{\prime} \ldots(C)$

Cardiac output $/ \mathrm{min} .=a^{\prime \prime}$. Body Size factor $+b^{\prime \prime}$.

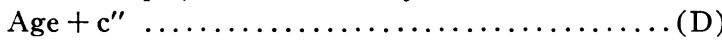

It is proposed to derive equations of this type for each sex with the accuracy the clata available permits.

\section{The data}

In Table I are listed the data for 50 healthy students. These determinations were made between 12 noon and 3.30 p.m. in June with laboratory temperatures varying from $21.2^{\circ} \mathrm{C}$ to $33.5^{\circ} \mathrm{C}$. The subjects had taken no strenuous exercise on the day of the test, and had not smoked or had anything to eat or drink for three hours previously. Each sat in a chair resting for 30 minutes and then lay down on the ballistocardiograph. At the end of 14 minutes a recording was taken, and another at the end of 21 minutes. The figures in Table $I$ are the average of these two determinations (3). 


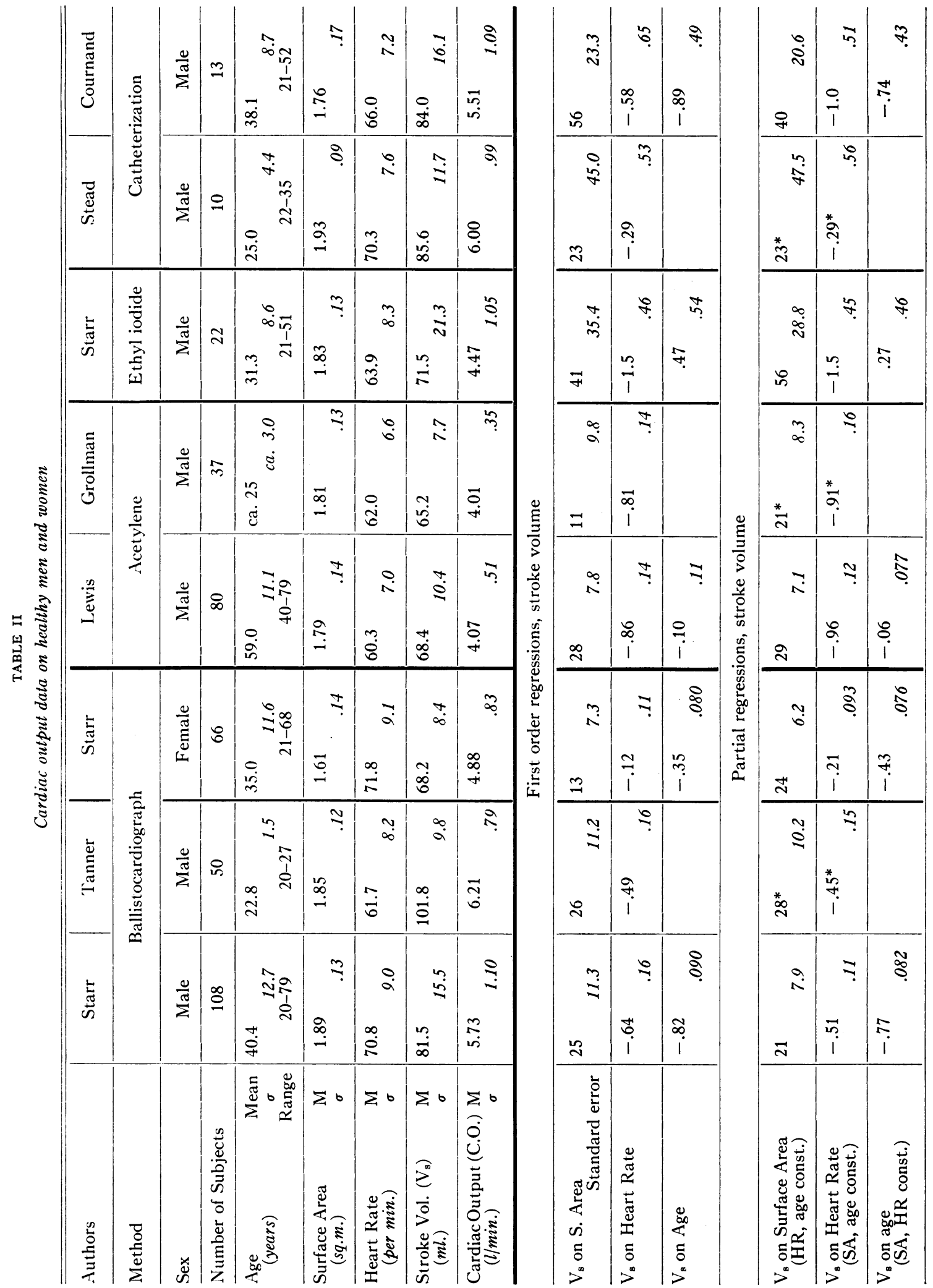


NORMAL STANDARDS FOR CARDIAC OUTPUT IN MAN

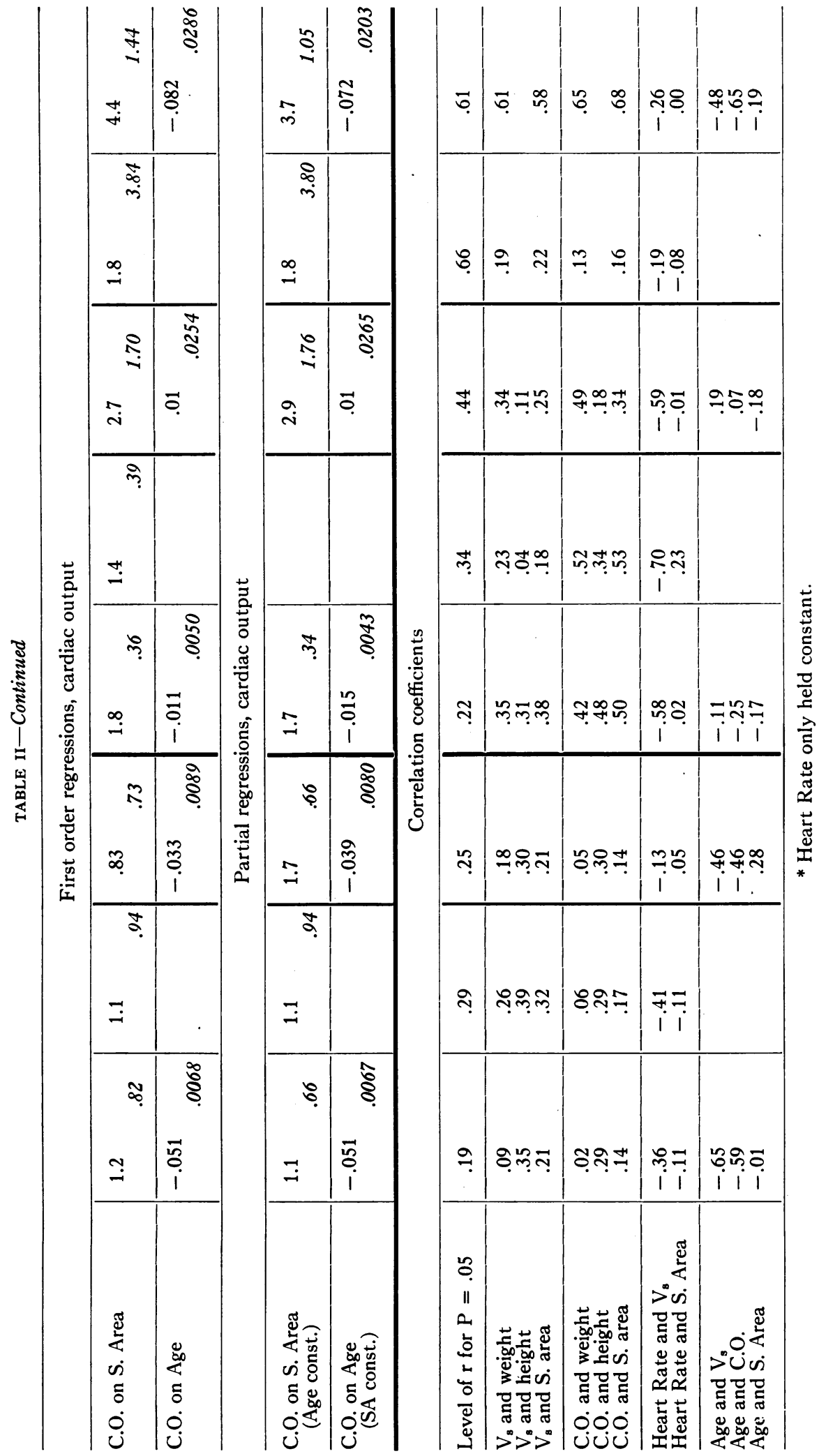


Table II sets out the biometric relations of all available studies which give full figures, including the heights and weights of the subjects. The first and third columns refer to the data of Starr, the second to the contents of Table I. These three columns are results from Starr's high-frequency ballistocardiograph, using the area formula of Starr, omitting A, the aortic cross-section area, and using 100 instead of 33 as the constant, the reason for which is given below.

The fourth and fifth columns refer to acetylene method results. Lewis studied 100 apparently healthy middleaged and old men (15), but only the data on the 80 subjects between the ages of 40 and 79 figure in the Table II calculations. Grollman's subjects were mostly medical students in the post-absorbtive state (12). The sixth column lists data obtained by Starr and his colleagues using ethyl iodide (16), and the last two columns are from cardiac catheterization studies.

Very few catheterization data are available on normal subjects. This being the case, it is all the more unfortunate that the two available series, due to Cournand et al. (17) and Stead et al. (18), do not agree. Stead's value for stroke volume for ten normal subjects ([18] their group 1 plus WP of group 4) of mean surface area 1.93 sq.m., heart rate 70.3 and age 25 , was $85.6 \mathrm{ml}$. Cournand's 13 subjects' mean stroke volume, when adjusted to Stead's means of surface area, heart rate and age, is $96.2 \mathrm{ml}$. or $96.6 \mathrm{ml}$. according to whether the adjustment is made using the regressions of Cournand's sample itself or of equation B3, below. In either case the difference between Stead's and Cournand's means is more than twice its standard error, and unlikely to be due to chance; it stems from a difference in arteriovenous oxygen difference, due to method, climate, choice of subjects, or some other factor. Thus the two series cannot be considered as from the same population and must be dealt with separately.

In the upper part of Table II means and standard deviations of the various variables are tabulated; the standard deviations are figures for the sample. The heart rates serve as a guide to the degree of rest and relaxation of the subjects; in three of the four large male series they are satisfactory, but Starr's ballistocardiograph group have rather high rates, perhaps because they were not in the post-absorptive state.

The middle part of Table II lists the regressions and partial regressions that we are concerned with, and which constitute the most important part of our analysis. These regressions are estimates of regressions in the population from which each sample was drawn, but some are, of course, much better estimates than others, due to the relative size of the samples. The standard errors are the figures in italics each below and to the right of the parent regression coefficient. The sampling error of the catheterization data in particular is distressingly large in relation to the making of standards.

The lower part of Table II lists various correlation coefficients of interest, and provides a way of judging the goodness of fit of the regression lines specified. The level of $\mathrm{r}$ for which $\mathrm{P}=.05$ is given, and for coefficients of this size the figure for twice the standard error of each coefficient will not be very much smaller than this.

In Table III are the more detailed statistics for age changes in cardiac output from the studies of Starr and of Lewis.

\section{BALLISTOCARDIOGRAPH STANDARDS}

Leaving a further consideration of Table II to the last part of the paper, we will now develop the appropriate standards for the Starr ballistocardiogram.

\section{The revised ballistocardiogram formula}

The dropping of $\mathrm{A}$, the cross-sectional area of the aorta, from Starr's ballistocardiogram formula (19) leaves the value of the constant in the formula indeterminate, and before we can give regression coefficients for stroke volume we must adopt some particular figure. The value to be chosen is that which will bring the mean normal figure for stroke volume calculated from the ballistocardiogram into line with the mean obtained by the catheter technique.

Using the Starr area formula without aortic cross-section and omitting the constant 33 (i.e., $\mathrm{V}_{\mathrm{s}}=\sqrt{(2 \mathrm{I} \text { area }+\mathrm{J} \text { area }) \sqrt{\mathrm{c}}}$ where the areas are measured in millimeter-seconds, and $280 \mathrm{gm}$. displace the light spot $1 \mathrm{~cm}$.), the mean value for Tanner's 50 men of average age 23 is $1.02 \mathrm{ml}$., and for Starr's 24 men (Table III) of average age 24 is $.92 \mathrm{ml}$. When both these means are adjusted for surface area and heart rate differences by equation $\mathrm{B} 3$, so that they correspond to the value of a group of surface area 1.80 sq.m. and heart rate 62 , Tanner's series mean is $1.00 \mathrm{ml}$. and Starr's $.94 \mathrm{ml}$. The difference between the two series is just twice its standard error; probably Tanner's subjects have higher outputs because they were all measured in the summer. A figure of about $.96 \mathrm{ml}$. would perhaps be the best all-theyear-round estimate. The question is whether to bring this up to Stead's mean catheter figure, or to Cournand's. I have chosen, pending more data, to bring it to the latter, chiefly because this makes the constant the convenient and self-evidently approximate figure of 100 . It is recommended that this be used in Starr's area formula, until further developments take place. 
TABLE III

Changes in cardiac output with age

\begin{tabular}{|c|c|c|c|c|c|c|c|c|c|c|c|c|c|c|}
\hline \multirow[b]{3}{*}{ Age } & & \multicolumn{8}{|c|}{ Starr: Ballistocardiograph } & \multicolumn{5}{|c|}{ Lewis: Acetylene } \\
\hline & & \multicolumn{5}{|c|}{ Males } & \multicolumn{3}{|c|}{ Females } & \multirow[b]{2}{*}{$40-49$} & \multirow[b]{2}{*}{$50-59$} & \multirow[b]{2}{*}{$60-69$} & \multirow[b]{2}{*}{$70-79$} & \multirow[b]{2}{*}{ 80-89 } \\
\hline & & $20-29$ & $30-39$ & $40-49$ & $50-59$ & $60-79$ & $20-29$ & $30-49$ & $50-69$ & & & & & \\
\hline Number & & 24 & 29 & 29 & 18 & 8 & 29 & 27 & 10 & 20 & 20 & 20 & 20 & 20 \\
\hline Surface Area & $\begin{array}{l}\mathrm{M} \\
\sigma\end{array}$ & $\begin{array}{r}1.86 \\
.13\end{array}$ & $\begin{array}{r}1.91 \\
.11\end{array}$ & $\begin{array}{r}1.92 \\
.14\end{array}$ & $\begin{array}{r}1.91 \\
.12\end{array}$ & 1.85 & $\begin{array}{r}1.57 \\
.14\end{array}$ & $\begin{array}{r}1.61 \\
.12\end{array}$ & 1.72 & $\begin{array}{r}1.82 \\
.14\end{array}$ & $\begin{array}{r}1.82 \\
.13\end{array}$ & $\begin{array}{r}1.79 \\
.15\end{array}$ & $\begin{array}{r}1.75 \\
.13\end{array}$ & $\begin{array}{r}1.68 \\
.15\end{array}$ \\
\hline Heart Rate & $\begin{array}{l}\mathrm{M} \\
\sigma\end{array}$ & $\begin{array}{r}70.6 \\
7.3\end{array}$ & $\begin{array}{r}71.5 \\
9.6\end{array}$ & $\begin{array}{r}67.8 \\
7.9\end{array}$ & $\begin{array}{r}72.2 \\
9.0\end{array}$ & 77.5 & $\begin{array}{l}73.6 \\
10.0\end{array}$ & $\begin{array}{r}70.7 \\
8.1\end{array}$ & 69.5 & $\begin{array}{r}61.1 \\
5.1\end{array}$ & $\begin{array}{r}60.8 \\
8.1\end{array}$ & $\begin{array}{r}60.1 \\
7.5\end{array}$ & $\begin{array}{r}58.7 \\
6.8\end{array}$ & $\begin{array}{r}62.9 \\
9.0\end{array}$ \\
\hline Stroke Volume & $\begin{array}{l}\mathrm{M} \\
\sigma\end{array}$ & $\begin{array}{l}92.4 \\
10.5\end{array}$ & $\begin{array}{l}86.7 \\
10.8\end{array}$ & $\begin{array}{l}82.1 \\
13.6\end{array}$ & $\begin{array}{l}66.8 \\
12.6\end{array}$ & 48.5 & $\begin{array}{r}70.4 \\
7.8\end{array}$ & $\begin{array}{r}67.4 \\
8.5\end{array}$ & 62.8 & $\begin{array}{l}71.3 \\
10.2\end{array}$ & $\begin{array}{l}67.4 \\
10.9\end{array}$ & $\begin{array}{r}68.1 \\
9.0\end{array}$ & $\begin{array}{l}66.5 \\
10.5\end{array}$ & $\begin{array}{l}60.0 \\
10.3\end{array}$ \\
\hline Cardiac Output & $\begin{array}{l}\mathrm{M} \\
\sigma\end{array}$ & $\begin{array}{r}6.51 \\
.88\end{array}$ & $\begin{array}{r}6.19 \\
.97\end{array}$ & $\begin{array}{r}5.52 \\
.86\end{array}$ & $\begin{array}{r}4.75 \\
.69\end{array}$ & 3.74 & $\begin{array}{r}5.19 \\
.85\end{array}$ & $\begin{array}{r}4.76 \\
.77\end{array}$ & 4.34 & $\begin{array}{r}4.32 \\
.57\end{array}$ & $\begin{array}{r}4.04 \\
.37\end{array}$ & $\begin{array}{r}4.06 \\
.48\end{array}$ & $\begin{array}{r}3.86 \\
.47\end{array}$ & $\begin{array}{r}3.74 \\
.65\end{array}$ \\
\hline I wave area & $\begin{array}{l}\mathrm{M} \\
\sigma\end{array}$ & $\begin{array}{r}21.7 \\
6.9\end{array}$ & $\begin{array}{r}19.9 \\
5.4\end{array}$ & $\begin{array}{r}17.0 \\
7.5\end{array}$ & $\begin{array}{l}9.7 \\
4.4\end{array}$ & 9.4 & $\begin{array}{r}12.2 \\
2.9\end{array}$ & $\begin{array}{r}11.3 \\
3.0\end{array}$ & 8.4 & & & & & \\
\hline $\mathrm{J}$ wave area & $\begin{array}{l}\mathrm{M} \\
\sigma\end{array}$ & $\begin{array}{l}50.1 \\
10.2\end{array}$ & $\begin{array}{l}42.4 \\
12.4\end{array}$ & $\begin{array}{r}39.6 \\
9.2\end{array}$ & $\begin{array}{r}30.0 \\
8.8\end{array}$ & 24.6 & $\begin{array}{r}32.2 \\
7.8\end{array}$ & $\begin{array}{r}27.9 \\
5.8\end{array}$ & 25.9 & & & & & \\
\hline $\mathrm{I} / \mathrm{J}$ & & 2.3 & 2.1 & 2.3 & 3.1 & 2.6 & 2.6 & 2.5 & 3.1 & & & & & \\
\hline $\begin{array}{l}\text { Average blood } \\
\text { pressure }\end{array}$ & $\begin{array}{l}\mathrm{M} \\
\sigma\end{array}$ & $\begin{array}{r}93.8 \\
7.8\end{array}$ & $\begin{array}{r}96.9 \\
5.7\end{array}$ & $\begin{array}{r}94.4 \\
8.4\end{array}$ & $\begin{array}{r}97.4 \\
7.3\end{array}$ & 111.4 & $\begin{array}{r}91.2 \\
6.9\end{array}$ & $\begin{array}{r}96.0 \\
9.7\end{array}$ & 106.5 & $\begin{array}{r}91.1 \\
6.6\end{array}$ & $\begin{array}{r}97.6 \\
7.9\end{array}$ & $\begin{array}{r}94.8 \\
8.5\end{array}$ & $\begin{array}{r}105.6 \\
11.2\end{array}$ & $\begin{array}{r}114.0 \\
13.0\end{array}$ \\
\hline
\end{tabular}

This new constant is probably too high; it assumes that persons lying at rest with an intracardiac catheter in place and a needle in the femoral artery are as truly basal as those lying in perfect comfort on the ballistocardiograph, and this is unlikely to be true. It places the mean level for ballistic stroke volumes considerably above that obtained by adding $18.5 \%$ to the old Starr formula, as suggested by Cournand (11), which gives a value of 60 for the constant, and leads to the rather low figure of $3.71 / \mathrm{min}$. for the cardiac output of healthy young men at rest. (Current model experiments, Professor Starr tells me, support the figure of 60 , all the same.) That at present we have no means of knowing absolute values from the ballistocardiogram is of no importance whatever so far as our standards are concerned. As used in practice they are independent of the constant and of any absolute level. When the constant changes as a result of further data accumulating, the regression coefficients in equations B3 and C3 below will change proportionately, but the standard error of estimate (see below, p. 577) will do likewise and the probability of a patient being abnormal will remain unaltered.

\section{The relation with body size}

There are two classifications of physique which command attention at the present time. One of these is due to Sheldon (4), and the other, resulting from applying the methods of factor analysis to measurement of the body, has reached its most advanced position in the hands of Burt (20). A discussion of the principles of these systems and of the relation between the two will be found elsewhere (21). The factor analysis yields a general Body Size factor, and several subsidiary factors such as the leptosomic, or linearity factor, which is the equivalent of Sheldon's ectomorphy. The Size factor is a measure of the simple largeness of the body; every measurement taken on the body correlates positively with it. It is really this Size Factor that we are attempting to consider when we regulate the dosage of a drug by body weight or calculate cardiac output per kilogram or per square meter. (We may thereafter, it is true, proceed to consider the relative amounts of more of less active tissue, the bone, muscle and fat proportions, but only after the general size has first been allowed for, or, in statistical language, 
partialled out.) An estimate of a man's Size Factor score may be obtained from a regression equation involving height and weight and sacrumheel length (22) and it is this Size Factor estimate which we should use as the first term in our multiple regression equation for cardiac output. However, another expression has been substituted, and this the familiar one, DuBois Surface Area (23). This surface area expression can be shown for men to correlate with the Size Factor estimate to the extent of .98 and its use therefore gives precisely the same result: it is a trifle simpler to theasure and compute and is already familiar to clinicians. It should be again emphasized, however, that the surface area is used simply because it provides a good estimate of the Size Factor and for no other reason. There is no implication whatever of theoretical physiological relations concerning surface area and cardiac output, such as caused controversy in the field of basal metabo$\operatorname{lism}(14,23,24)$. The figure used for weight should be the subject's usual weight in health: under no circumstances should any so-called "ideal" weights be used, which are merely methods of telling what weight a given person would have if he were somebody else of entirely different appearance. I have used surface area as equivalent to the Size Factor for women as well as men, and the propriety of doing so might well be questioned: data on the subject are lacking.

The regression of stroke volume on surface area for ballistocardiograph data can be seen in Table II. The figure for women is less than that for men, but this seems to be due to the existence of a positive relation between surface area and age in the series of women, but not in the men. Partial regressions with age constant give almost identical figures for both sexes.

Heart rate and body size seem to be independent of each other. The heart rate has insignificantly small correlations with height, weight and surface area in all the data of Table II. The large series of Boas and Goldschmidt (25) and Harris and Benedict (14) gave almost exactly zero correlations. We may conclude that resting heart rate in the human is unrelated to the Size Factor.

Beyond the general Size Factor, one may suspect that a person's body build may influence his cardiac output. In the 50 young men of my series, however, no sure relation could be demon- strated between heart rate, stroke volume or cardiac output and any of the Sheldon components (3). Correlations with Burt's leptosomic factor scores (taken to increase as linearity or ectomorphy increases, contrary to the usage in my previous study [21]) were only .18 for stroke volume and .19 for cardiac output, either of which would be expected to occur once in five samplings of a population in which there was no correlation at all; and .06 for heart rate. Thus at present, though some quite small positive relation between stroke volume and linearity of build may exist, the inclusion of body build factors other than general size would not substantially improve our standards.

\section{Stroke volume and heart rate}

The relationship between stroke volume and heart rate is an inverse one. There is good agreement, particularly in the partial regression, between the two male ballistocardiograph series, but the figure for women seems only to be about half as large.

\section{Stroke volume and age}

The regressions and correlations are in Table II and some more detailed statistics in Table III. Starr's male data show a very marked decrease with age, with a linear correlation of -.65 . The female regression is again about half the male.

\section{The standard regression equations}

We are now in a position to assign values to the coefficients in the regression equations $B$ and $\mathrm{D}$, for the ballistocardiograph. These values are the partial regressions in Table II ; but they have been rounded off to avoid giving an unwarranted appearance of high accuracy. The figures for stroke volume on surface area are sufficiently close for the value 25 to be used for males and females; for stroke volume on heart rate, -.50 covers adequately both male series. We then have $:^{3}$

Estimate $\mathrm{V}_{\mathbf{s}}(\mathrm{ml})=$.25 (S. Area - Mean S. Area $)-$ .50 (H. Rate - Mean H. Rate) - .80 (Age-Mean Age) + Mean $V_{s} \ldots \ldots \ldots \ldots . .$. Men, ballisto (B1)

${ }^{3} \mathrm{~A}$ set of somewhat different equations based on preliminary calculations has appeared in the Proc. Phila. Physiol. Society, Amer. J. M. Sc., 1948, 216, 598. The present equations replace those preliminary ones. 
and

Estimate $\mathrm{V}_{\mathrm{s}}(\mathrm{ml})=25$ (S. Area - Mean S. Area $)-$ .20 (H. Rate - mean H. Rate) -.40 (Age - Mean Age) + Mean $V_{s} \ldots \ldots \ldots \ldots$ Women, ballisto (B2)

The partial regression coefficients in the equations refer to population values, but the figures to be inserted for the means of stroke volume, surface area, heart rate and age should perhaps be taken by each separate laboratory from the usual run of its own data. In this way, though the mean stroke volume figures may differ in different laboratories due to variations in method, climate and so forth, estimates of $V_{\mathbf{s}}$ will always be couched at the same level as the actually recorded measurements. We must perforce assume that the standard deviation is unaffected by such changes in the mean as we have to deal with. For heart rate, at least, the figures of different series agree very well, both as to mean and standard deviation $(3,12,14,25)$. The population mean for resting males may be taken as approximately 62 , and the standard deviation as about 8 . For women these figures are 69 and 9 . These values only apply if really sufficient time of resting is allowed the subject before determination; at least 15 and perhaps $20 \mathrm{~min}$ utes. The subject should preferably be in the post-absorptive state.

Using 100 as the constant in the ballistocardiograph equation, the mean of Starr's series is 82 ml. for men and $68 \mathrm{ml}$. for women. Putting in the means of his samples also for surface area, heart rate and age, we finally have:

Estimate $\mathrm{V}_{\mathrm{s}}(\mathrm{ml})=.25 \mathrm{~S}$. Area $-.50 \mathrm{H}$. Rate -.80 Age $+103 \ldots \ldots \ldots \ldots \ldots \ldots \ldots . \ldots . \ldots . \ldots$ Men, ballisto (B3)

Estimate $\mathrm{V}_{\mathrm{s}}(\mathrm{ml})=.25 \mathrm{~S}$. Area $-.20 \mathrm{H}$. Rate -.40 Age $+56 \ldots \ldots \ldots \ldots \ldots \ldots \ldots \ldots \ldots \ldots \ldots \ldots \ldots$ Women, ballisto (B4)

These equations, as has been emphasized, should be regarded only as major terms in longer, more accurate, expressions. They are inapplicable below the age of 20 , and of doubtful validity above the age of 70 . The standard errors of the coefficients have been indicated in Table II. The multiple correlation of $\mathrm{V}_{\mathrm{s}}$ in these equations is .77 for men, and .50 for women; that is, surface area, heart rate and age account for $53 \%$ of the variance of stroke volume estimated by the ballistocardiograph in men, and $25 \%$ of the variance in women.

By substituting an individual's measurements in the relevant equation, we obtain an estimate of what his stroke volume should be on the basis of his surface area, heart rate and age. We then discover experimentally his actual stroke volume. Naturally the actual stroke volume differs from the estimate by a certain amount, which we will call $d$. The question to which the clinician requires the answer, and to which all the above development has been leading is simply "What is the likelihood that this man's difference, $d$, is due merely to sampling from the normal population?". This is a more valid form of the cruder question "Is this man's stroke volume normal or not?", for if the likelihood of the man's difference having arisen just by sampling is small, the man is presumably not from the normal population, and is thus from another, abnormal one. It has been customary, with the ratio standard, to say that the man is abnormal if the difference between his actual value and the mean value, or standard, is $20 \%$ of the mean. This usage has little statistical foundation, and with the regression equation standard we can replace it with a more valid and more informative device. The estimates we make from the regression equation have a standard error, and a guide to the likelihood of a given man not coming from the normal population is directly given by the ratio of the difference, $d$, to this standard error. The standard error is given by

$$
\sigma_{\mathrm{est}}=\sigma_{\mathrm{vs}} \sqrt{1-\mathrm{R}^{2}},
$$

where $\mathrm{R}$ is the multiple correlation coefficient. Using the figures already given, we have $\sigma_{\text {est }}=$ $16 \sqrt{1-.53}=11 \mathrm{ml}$. for men and $8.6 \sqrt{1-.25}$ $=7.5 \mathrm{ml}$. for women.

The interpretation of $d / \sigma_{\text {est }}$ is that of the ordinary critical ratio and from it the clinician can tell how much confidence to place in the idea that the man may be abnormal. The confidence limits usually used by statisticians are \pm 2 for the ratio, which would lead to five normal men in 100 being classed as abnormal. Thus we may roughly place the limits of stroke volume normality for males at $\pm 22 \mathrm{ml}$. from the regression estimate. (Though these limits seem reasonably appropriate, they are quite arbitrary and stricter ones may be taken if the clinician desires; for example at \pm 2.5 , which would lead to wrong classification only once in 100 people.)

Heart rate. To complete equation (C) for predicting heart rate, we need only to employ the 
mean figures for both sexes. The standard deviations of the distributions of heart rates in the population are known. Again, each laboratory should use its own mean values. Whether or not a given heart rate should be considered abnormal may be tested in the same way as for stroke volume.

Cardiac output. The equivalent equations for cardiac output are:

Estimate C.O. $(1 / \mathrm{min})=$.1.1 (S. Area - Mean S. Area $)$

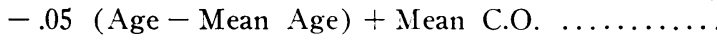

........................ ballisto (D1)

and

Estimate C.O. $(1 / \mathrm{min})=$.1.7 (S. Area - Mean S. Area $)$

-.04 (Age - Mean Age) + Mean C.O. .............

......................... ballisto (D2)

With the mean values of Starr's series inserted, these become :

Estimate C.O. $(1 / \mathrm{min})=.1.1 \mathrm{~S}$. Area -0.5 Age +5.5 . $\ldots \ldots \ldots \ldots \ldots \ldots \ldots$ Men, ballisto (D3)

Estimate C.O. $(1 / \mathrm{min})=.1.7 \mathrm{~S}$. Area -.04 Age +3.5 . ....................... Women, ballisto (D4)

These equations like those for stroke volume are subject to later modification of coefficients as more data accumulate, and are applicable only between the ages of 20 and 70 . The multiple correlation coefficient for men is .61 and for women .54 , surface area and age thus accounting for $37 \%$ of the variance of cardiac output in resting men, and $29 \%$ of the variance in women. It may be recalled that a similar equation for basal oxygen consumption yields a multiple correlation of about .85 which accounts for $73 \%$ of variance (14). Thus our standards are only about half as effective at catching the abnormals as are the B.M.R. standards. Any future cardiac output standard that does detect abnormals as efficiently as do the present B.M.R. standards will have to be very much more complicated than those developed here.

The last point may be brought home by a consideration of the interpretation of $d$, the difference, as before, of the actual cardiac output from the estimated. Again we have

$$
\sigma_{\text {est }}=\sigma_{\text {C.o. }} \sqrt{1-\mathrm{R}^{2}} \text {. }
$$

The higher $\mathrm{R}$, the smaller $\sigma_{\text {est }}$, and thus the smaller the difference, $d$, to place a man outside the normal limits. We have this time $\sigma_{\text {est }}=$ $1.1 \sqrt{1-.37}=.871 / \mathrm{min}$. for men and $.84 \sqrt{1-.29}$ $=.711 / \mathrm{min}$. for women. Confidence limits would again be \pm 2 for the radio $d / \sigma_{\text {est }}$. Thus the limits of cardiac output normality for males would be roughly at $\mathrm{a} \pm 1.7 \mathrm{1} / \mathrm{min}$. difference from the regression estimate for men, and $1.41 / \mathrm{min}$. difference for women.

Use of the standard equations. We may conclude this section with a couple of practical examples of the use of the new standards. Subject No. 5 of the Tanner ballistocardiograph series was aged 23 ; his height was $176 \mathrm{~cm}$., weight $77.3 \mathrm{~kg}$., and Dubois surface area 1.92 sq.m. After 20 minutes lying at rest, his heart rate was 73 per min. and calculation from his ballistocardiogram impacts gave a stroke volume of $91 \mathrm{ml}$.

To answer the question whether this man is abnormal substitute his surface area, heart rate and age in equation B3 using the Starr series means. The estimated stroke volume figure for such an individual is $96 \mathrm{ml}$. The difference between the value found and that predicted is 5 , and the critical ratio of this difference to its standard error is $5 / 11=0.5$. Thus there is no reason to regard this man as abnormal. The report on this man would read "actual stroke volume $91 \mathrm{ml}$., standard estimate $96 \mathrm{ml}$., critical ratio 0.5 , normal." It is instructive to consider how this man would have fared by reference to the old standards. His per-surface area estimate is $106 \mathrm{ml}$. and his per-weight estimate no less than $112 \mathrm{ml}$. On the basis of the weight standard he would be judged abnormal, with a stroke volume $21 \%$ below average.

A second man, F., aged 69, of surface area 1.89 sq.m., had a heart rate of 64 and a stroke volume estimated by the ballistocardiogram of 42 $\mathrm{ml}$. He complained of nothing, worked normally, and was tested merely to add to the collection of normal data. His stroke volume, however, seems small. Is it likely he is abnormal? Substitution in equation B3 gives his regression estimate as $63 \mathrm{ml}$. The difference between the values found and estimated is $21 \mathrm{ml}$. and the critical ratio is $21 / 11=1.9$, on the borders of conventional statistical significance. ${ }^{4}$ It is therefore relatively un-

* This is using the hypothesis that the man is abnormal, i.c., has either too low or too high a stroke volume. But if the hypothesis is that his output is too small (probably the more important one clinically, since other factors will usually lead one to suppose abnormality of one particular sort), then the level of normality should be taken at 
likely that this man has a normal heart, despite his history; and, indeed, a few years later, he became aware of having coronary disease.

The cardiac output estimates for these two men may be calculated from equation (D3) and the likelihood of their being abnormal similarly assessed; the information yielded for these two cases is the same as above.

\section{COMPARISON OF BALLISTOCARDIOGRAPH WITH OTHER METHODS}

A few of the relations between the various cardiac output methods implied by the sea of figures in Table II seem worth fishing up and examining shortly, even if their subsequent fate is to be thrown back in. Most of this discussion concerns males only.

\section{Stroke volume and surface area}

On the present data there is little reason to suppose that any significant difference in this regression exists between the ballistocardiograph, acetylene and catheterization methods. Cournand's series had a curiously large range of surface areas, with a sample standard deviation of .17 compared to all the other samples' .13 or .14 . Perhaps this was done on purpose with the idea of covering a good range of sizes in normals; it may well be responsible for tipping up the regression line if the relationship is not really quite as linear as we would like to suppose.

There is a suspicion that the ballistocardiogram area formula may lead to higher correlations with height and lower with weight than do the other methods; possibly the length of the body influences the form of the I or J waves. Starr has himself suggested that body length should be allowed for in the ballistocardiograph formula (19), and Nickerson has included it in a revised formula for use with his low frequency instrument (8). A long aorta contains a greater mass of blood than a short one, and it is conceivable also that the time between the blood hitting the arch and the bifurcation should be larger in tall men than in short ones. Calculations on my series of 50 subjects does indeed show that the $\mathrm{J}$ wave area has with bodily stature a specific relation of its own; a relation, that is, not shared by the I wave.

a critical ratio of 1.65 instead of 2 . One then misclassifies as too lori outputs of five people in 100 .

\section{Stroke volume and heart rate}

There appears to be a significant difference in this regression between the acetylene and the ballistocardiograph methods. As heart rate rises, stroke volume apparently decreases nearly twice as fast by the acetylene as by the ballistocardiograph. At least part of the reason for this seems clear enough. In both acetylene studies the second samples of rebreathed air were taken 23-25 seconds after the beginning of rebreathing, and the evidence presented by Hamilton (26) that considerable recirculation has occurred during this time seems entirely convincing. The greater the heart rate, the less circulation time (27-29), the more the recirculation, and therefore the lower, apparently, the stroke volumes: part of the negative correlation in the acetylene data is artefactual. For this reason I would be inclined to place the most likely partial regression for the catheter method near to -.5 rather than -1.0 ; the differences in the two catheter series are presumably due mainly to sampling error.

\section{Stroke volume and age}

There are only two considerable sets of data on age changes, and unfortunately they are in complete disagreement. Starr's ballistocardiograph data show a large decrement with age, while Lewis's acetylene data have hardly any decrement at all (Table III).

The disagreement in results is probably due to both sampling bias and to the difference in method. Lewis's subjects on which the regressions are calculated covered the age range 40-79 and were selected as being healthy men free from cardiovascular as well as other symptoms. It is perhaps not unreasonable to suppose that towards the end of the age span the subjects so qualified were those who had maintained fairly high cardiac outputs. Others, who would enter into lower age group standards as perfectly normal, and who subsequently had suffered a (not unusual) decline of output might perhaps not be free of slight symptoms. In short, there may have been selection for high cardiac outputs at the upper end of the age distribution. Secondly, in the acetylene method the amount of recirculated blood may well decrease with advancing age $(27,28,30)$ and if so cardiac outputs would appear to increase. 
Thus a true drop would be marked by an artefactual rise.

The only catheterization figure, from Cournand's series of 13 subjects between the ages of 21 and 52, agrees with the ballistocardiogram figure, but its standard error is so high that the agreement cannot be taken very seriously. Somewhat in agreement's favour, however, are the data from the low-frequency ballistocardiograph of Nickerson (8). The correlation of these results and catheterization was .83 (which corrected for attenuation reaches .9) and no change occurred with increasing age in the relation between the results secured by the two methods.

There is on the other hand an argument in favour of the ballistocardiograph overemphasizing the decrement with age, and doing so in a way which may prove of great value to clinicians in the future. The area under the $I$ and $J$ waves reflects not only the stroke volume, but also the ejection curves of the ventricles (31). If the ejection curve changes, the formula for stroke volume becomes relatively inapplicable. Though as yet there does not seem to be any direct evidence that the ejection curve does change with age, that it should do so would be entirely consonant with general ideas of aging, and indirect evidence may be found, perhaps, in electrocardiographic changes (32). Such a change must be of the sort which will lead to a diminution of the area under the I and J curves, even when the actual stroke volume remains constant. It must not, however, alter the ratio of the $J$ area to the I area, since this remains more or less unchanged as age advances (Table III). To satisfy these requirements the nature of the change can be predicted on the basis of Hamilton's curves (31, Figure 8) to consist of a ventricular contraction of usual initial speed and force but less sustained than normal; and this seems not an unreasonable thing to occur with myocardial aging.

Probably the true partial regression of stroke volume on age lies between .6 and $.8 \mathrm{ml}$. per year, over the age range considered. This assumes a linear decrease of stroke volume with age, which, though unlikely to be actually true, is the only assumption warranted by the extant data. It also implies the conclusion that the arteriovenous oxygen difference rises with age, since the oxygen consumption correlation is only about -.3 (33) compared to the stroke volume figure of between -.5 and -.65 . Pending further developments, it would be best to use the same regression for cardiac catheter method standards, if these are needed, as for the ballistocardiogram, remembering this may exaggerate the age effect slightly. There is great need for simultaneous studies by the ballistocardiograph and catheterization methods upon normal subjects of different ages. When the position is clarified, it may well be that one of the chief clinical values of the ballistocardiogram will lie in measuring not stroke volume, but myocardial changes and efficiency.

\section{Cardiac output and sex}

The only extensive data on the cardiac output of normal women are those of Starr. When the stroke volume of the 20-29 year old women is adjusted by means of equation $\mathrm{B} 4$ to the same surface area and heart rate as Starr's 20-29 year old males, it is smaller than the male figure in the ratio .85 . The corresponding ratio for the $30-49$ year old women is .89 .

The resting heart rate of women, on the other hand, is about $10 \%$ higher than that of men (14, 25 ), and since heart rate is not related to body size, this is irrespective of size. Thus the cardiac output per minute would be more nearly the same than is stroke volume. The ratios for Starr's groups are smaller than would be expected, probably because the subjects have greater than basal heart rates; they are .87 and .91 for the two age groups.

Heart rate and stroke volume seem to be more independent in women than in men, but this result should be treated with reserve, as the difference between the two regressions lies only at the level of $\mathrm{P}=.075$ even if the comparison is made with both Starr and Tanner male data. Stroke volume in women apparently declines somewhat less rapidly with age than in men, and in this case the probability of the regression difference having arisen by chance sampling is only 1 in $70(\mathrm{P}=$ $.014)$. The equivalent partial regressions of cardiac output on age, however, are not significantly different. 
Standards for catheterization data

The data are too meagre and in too little agreement to warrant the creation at present of special catheter standards. It is recommended that the ballistocardiograph standards be used with catheter data pending further developments, and with full realization of the possible errors incurred. The fact that in some disorders the ballistocardiograph may give results widely different from the catheter, due to changes in the cardiac ejection curve, is irrelevant so far as the use of normal standards is concerned: under such circumstances the ballistocardiograph standards would relate better to the catheter results than to the ballistic ones. With the latter, one can imagine a situation where a true increase in stroke volume may be accompanied by a weakened ejection, one fault compensating for the other. Ultimately standards for the ejection curves themselves will have to be made.

\section{SUM MARY}

1. Ballistocardiographic cardiac output data, blood pressure, mouth temperature and somatotype are reported for 50 healthy young men at rest.

2. The reliability of cardiac output methods is discussed, and it is shown that agreement between the ballistocardiograph and catheterization methods is very good, if their respective reliabilities are taken account of.

3. The present use of ratio standards such as per-weight and per-surface area involves a fallacy and leads to erroneous results, sometimes of practical importance; this is discussed.

4. The construction of normal standards for cardiac output by means of multiple regression equations is discussed and the appropriate standards derived for the Starr ballistocardiograph stroke volume and cardiac output for men and women. Their clinical use is illustrated.

5. To bring the Starr ballistocardiograph data into line with Cournand's catheterization values, it is recommended that, when aortic cross-section is dropped from the Starr wave area formula for stroke volume, the constant 33 be provisionally replaced by 100 .

\section{ACKNOWLEDGMENTS}

I wish most gratefully to express to Professor Starr my appreciation of his untiring advice and help, and my thanks for the use of unpublished records; the personal data quoted in this paper were obtained while I was working in his laboratory. At the time I was supported as a wartime Rockefeller student and I wish to thank these authorities for providing me, and many others, with opportunities of very great value. I wish also to thank Professor Sir Cyril Burt for the most prompt cooperation and advice he gave during the later stages of this work.

\section{BIBLIOGRAPHY}

1. Tanner, J. M., On the fallacy of clinical per-weight and per-surface area standards, and their relation to spurious correlation. J. Appl. Physiol. In press.

2. Starr, I., On the later development of heart disease in apparently healthy persons with abnormal ballistocardiograms. Eight- to ten-year after-histories of 90 persons over 40 years of age. Am. J. M. Sc., 1947, 214, 233.

3. Tanner, J. M., Intercorrelations between cardiovascular variables in healthy men, and the relation of physique to these and other variables. Proc. Physiol. Soc. of Philadelphia; Am. J. M. Sc., 1944, 207, 684.

4. Sheldon, W. H., Stevens, S. S., and Tucker, W. B., The Varieties of Human Physique. Harpers, New York, 1940.

5. Starr, I., and Schroeder, H. A., The ballistocardiogram. II. Normal standards, abnormalities commonly found in diseases of the heart and circulation, and their significance. J. Clin. Invest., 1940, 19, 437.

6. Starr, I., Rawson, A. J., Schroeder, H. A., and Joseph, N. R., Studies on the estimation of cardiac output in man, and of abnormalities in cardiac function, from the heart's recoil and the blood's impacts; the ballistocardiogram. Am. J. Physiol., 1939, 127, 1.

7. Grollman, A., The Cardiac Output of Man in Health and Disease. C. C. Thomas, Springfield, Illinois, 1932.

8. Nickerson, J. L., Warren, J. V., and Brannon, E. S., The cardiac output in man; studies with the low frequency, critically-damped ballistocardiograph, and the method of right atrial catheterization. J. Clin. Invest., 1947, 26, 1.

9. Warren, J. V., Stead, E. A., Jr., and Brannon, E. S., The cardiac output in man; a study of some of the errors in the method of right heart catheterization. Am. J. Physiol., 1946, 145, 458.

10. Peters, C. C., and van Voorhis, W. R., Statistical Procedures and Their Mathematical Bases. McGraw-Hill, New York, 1940. 
11. Cournand, A., Ranges, H. A., and Riley, R. L., Comparison of results of the normal ballistocardiogram and a direct Fick method in measuring the cardiac output in man. J. Clin. Invest., 1942, 21, 287.

12. Grollman, A., Physiological variations in the cardiac output of man. VI. The value of the cardiac output of the normal individual in the basal, resting condition. Am. J. Physiol., 1929, 90, 210.

13. Millar, W. G., and Ross, T. F., Aortic size, status lumphaticus, and accidental death. J. Pathol. \& Bact., 1942, 54, 455.

14. Harris, J. A., and Benedict, F. G., A biometric study of basal metabolism in man. Carnegie Institute of Washington publication No. 279, 1919.

15. Lewis, W. H., Jr., Changes with age in the cardiac output in adult man. Am. J. Physiol., 1938, 121, 517.

16. Starr, I., Donal, J. S., Margolies, A., Shaw, R., Collins, L. H., and Gamble, C. J., Studies of the heart and circulation in disease; estimations of basal cardiac output, metabolism, heart size and blood pressure in 235 subjects. J. Clin. Invest., 1934, 13, 561.

17. Cournand, A., Riley, R. L., Breed, E. S., Baldwin, E. F., and Richards, D. W., Measurement of cardiac output in man using the technique of catheterization of the right auricle or ventricle. J. Clin. Invest., 1945, 24, 106.

18. Stead, E. A., Jr., Warren, J. V., Merrill, A. J., and Brannon, E. S., The cardiac output in male subjects as measured by the technique of right atrial catheterization. Normal values, with observations on the effects of anxiety and tilting. J. Clin. Invest., 1945, 24, 326.

19. Starr, I., Present status of the ballistocardiograph as a means of measuring cardiac output. Federation Proc., 1945, 4, 195.

20. Burt, C., and Banks, C., A factor analysis of body measurements for British adult males. Ann. Eugenics, 1947, 13, 238.
21. Tanner, J. M., The morphological level of personality. Proc. Roy. Soc. Med., 1947, 40, 301.

22. Burt, C., Personal communication.

23. DuBois, E. F., Basal Metabolism in Health and Disease. Bailliere, Tindall and Cox, London, 1936, 3rd edition.

24. Benedict, F. G., Vital energetics; a study in comparative basal metabolism. Carnegie Institute of Washington publication No. 503, 1938.

25. Boas, E. P., and Goldschmidt, E. F., The Heart Rate. C. C. Thomas, Springfield, I1l., 1932.

26. Hamilton, W. F., Notes on the development of the physiology of cardiac output. Federation Proc., 1945, 4, 183.

27. Blumgart, H. L., and Weiss, S., Studies on the velocity of blood flow. II. The velocity of blood flow in normal resting individuals, and a critique of the method used. J. Clin. Invest., 1927, 4, 15.

28. Blumgart, H. L., and Weiss, S., Studies on the velocity of blood flow. VII. The pulmonary circulation time in normal resting individuals. J. Clin. Invest., 1927, 4, 399.

29. Bailey, H. A., Dumas, L. W., and Lackey, R. W., The relation of physiologic variables to circulation time. J. Lab. \& Clin. Med., 1946, 31, 584.

30. Lange, K., and Boyd, L. J., Objective methods to determine the speed of blood flow and their results (fluorescein and acetylene). Am. J. M. Sc., 1943, 206, 438.

31. Hamilton, W. F., Dow, P., and Remington, J. W., The relationship between the cardiac ejection curve and the ballistocardiographic forces. Am. J. Physiol., 1945, 144, 557.

32. Mazer, M., and Reisinger, J. A., An electrocardiographic study of cardiac aging based on records at rest and after exercise. Ann. Int. Med., 1944, 21, 645.

33. Lewis, W. H., Changes with age in the basal metabolic rate in adult man. Am. J. Physiol., 1938, 121,502 . 